\title{
Jejunum and Ileum Neuroendocrine Tumor pN2 TNM Finding v8
}

National Cancer Institute

\section{Source}

National Cancer Institute. Lejunum and Ileum Neuroendocrine Tumor pN2 TNM Finding v8. NCI Thesaurus. Code C135118.

Jejunum and ileum neuroendocrine tumor with large mesenteric masses (larger than 2 $\mathrm{cm}$ ) and/or extensive nodal deposits (12 or greater), especially those that encase the superior mesenteric vessels. (from AJCC 8th Ed.) 